\title{
Nerve Terminal Withdrawal from Rat Neuromuscular Junctions Induced by Neuregulin and Schwann Cells
}

\author{
Joshua T. Trachtenberg and Wesley J. Thompson \\ Department of Zoology, The University of Texas at Austin, Austin, Texas 78712
}

Schwann cells (SCs) that cap neuromuscular junctions (nmjs) play roles in guiding nerve terminal growth in paralyzed and partially denervated muscles; however, the role of these cells in the day-to-day maintenance of this synapse is obscure. Neuregulins, alternatively spliced ligands for several erbB receptor tyrosine kinases, are thought to play important roles in cell-cell communication at the $\mathrm{nmj}$, affecting synapse-specific gene expression in muscle fibers and the survival of terminal SCs during development. Here we show that application of a soluble neuregulin isoform, glial growth factor II (GGF2), to developing rat muscles alters terminal SCs, nerve terminals, and muscle fibers. SCs extend processes and migrate from the synapse.
Nerve terminals retract from acetylcholine receptor-rich synaptic sites, and their axons grow, in association with SCs, to the ends of the muscle. These axons make effective synapses only after withdrawal of GGF2. These synaptic alterations appear to be induced by the actions of neuregulin on SCs, because SC transplants growing into contact with synaptic sites also caused withdrawal of nerve terminal branches. These results show that SCs can alter synaptic structure at the $\mathrm{nmj}$ and implicate these cells in the maintenance of this synapse.

Key words: Schwann cells; neuregulin; neuromuscular junction; development; axonal withdrawal; synaptic stability.
The cellular and molecular interactions that maintain synapses are incompletely understood. Evidence from the mammalian neuromuscular junction (nmj) suggests that retrograde factors supplied by postsynaptic muscle fibers are required for the maintenance of motor nerve terminals. Loss of acetylcholine receptors (AChRs) from a portion of the synapse (Rich and Lichtman, 1989a; Balice-Gordon and Lichtman, 1993; Balice-Gordon and Lichtman, 1994) or degeneration of the muscle fiber itself (Rich and Lichtman, 1989b; Van Mier and Lichtman, 1994) precedes a rapid, partial loss of nerve terminal branches. Similar studies in frog muscles suggest that signals in the synaptic basal lamina are capable of regulating the maintenance of nerve terminal branches. After the degeneration of postsynaptic muscle fibers in frogs, nerve terminals maintain their branches and continue to recycle vesicles for months (Dunaevsky and Connor, 1995). Furthermore, regenerating axons can differentiate nerve terminal specializations on "basal lamina ghosts" in the absence of postsynaptic muscle fibers (Marshall et al., 1977; Sanes et al., 1978; Glicksman and Sanes, 1983; Kuffler, 1986). Consistent with this view, a number of signaling proteins that influence motor nerve terminal differentiation have been identified in the synaptic basal lamina (Campagna et al., 1995; Noakes et al., 1995; Gautam et al., 1996).

SCs that cap nerve terminals at nmjs (terminal SCs) may also regulate some aspects of nerve terminal differentiation and main-

Received April 8, 1997; revised June 6, 1997; accepted June 6, 1997.

This work was supported in part by a grant from National Institutes of Health (NS20480). We thank M. Marchionni and C. Kirk at Cambridge Neuroscience Inc. for their generous gift of rhGGF2 and advice in its use, G. Gage and C. Schlegel for assistance with the artwork, L. Sutton for his technical assistance, and Drs. S. Astrow, R. Balice-Gordon, D. Kopp, J. Lubischer, M. Shankland, and Y-J Son for their comments on earlier versions of this manuscript.

Correspondence should be addressed to Wesley J. Thompson, Department of Zoology, The University of Texas at Austin, Austin, TX 78712.

Dr. Trachtenberg's present address: Department of Physiology, The University of California, San Francisco, 513 Parnassus Avenue, San Francisco, CA 94143.

Copyright (C) 1997 Society for Neuroscience $0270-6474 / 97 / 176243-13 \$ 05.00 / 0$ tenance. The processes that these cells extend in response to muscle denervation or paralysis appear to serve as substrates for nerve growth and can cause nerve terminals to initiate growth (Son and Thompson, 1995). The basal lamina protein S-laminin/ laminin $\beta 2$ appears to maintain synaptic differentiation in part by preventing SCs from intruding between the nerve terminal and muscle fiber (Patton and Sanes, 1996). Additionally, terminal SCs express nitric oxide synthase (Descarries et al., 1996), an enzyme proposed to play a role in associative synaptic plasticity.

Neuregulins, a family of alternatively spliced ligands expressed by embryonic and adult motor neurons and muscle fibers (Marchionni et al., 1993; Moscoso et al., 1995), are thought to influence the genesis and maturation of neuromuscular synapses by regulating gene expression in muscle fibers and terminal SCs. Concentrated at nmjs by the early postnatal period (Goodearl et al., 1995; Jo et al., 1995), neuregulins have been demonstrated to promote the expression of AChRs and sodium channels from cultured myotubes (Harris et al., 1988; Martinou et al., 1991; Corfas and Fischbach, 1993; Altiok et al., 1995; Chu et al., 1995; Jo et al., 1995) and to mediate the survival of terminal SCs at developing nmjs (Trachtenberg and Thompson, 1996). These actions are likely mediated by activation of the erbB family of receptor tyrosine kinases (Carraway and Cantley, 1994) expressed in terminal SCs and muscle fibers (Cohen et al., 1992; Altiok et al., 1995; Moscoso et al., 1995; Zhu et al., 1995; Grinspan et al., 1996).

Whether neuregulins influence synaptic plasticity and stability, however, is unclear, because mice homozygous null for neuregulin (Meyer and Birchmeier, 1995) or the receptors erbB2 (Lee et al., 1995) or erbB4 (Gassmann et al., 1995) die by embryonic day 10.5, a time at which nmjs have not yet begun to form. In mice heterozygous null for a subset of neuregulin isoforms, however, aspects of neuromuscular synaptic transmission are altered (Sandrock et al., 1996), suggesting that neuregulin plays important roles in regulating the efficacy of neurotransmission at this synapse. Here, by 
examining changes in the morphology and physiology of nmjs exposed to elevated levels of neuregulin in vivo, we report that neuregulin, through its actions on terminal SCs, regulates the stability of motor nerve terminals at developing nmjs.

\section{MATERIALS AND METHODS}

GGF2 administration. Recombinant human GGF2 (Cambridge Neuroscience, Cambridge, MA) was administered once daily via subcutaneous injection into the crus of Wistar rats. Injections were made medially and laterally, $5 \mu \mathrm{l}$ on each side of one hindlimb. Glial growth factor II (GGF2) was used at a concentration of $0.73 \mu \mathrm{g} / \mu \mathrm{l}$ and was dissolved in a vehicle containing $1 \%$ bovine serum albumin, $20 \mathrm{~mm}$ sodium acetate, $100 \mathrm{~mm}$ arginine, $1 \%$ mannitol, and $100 \mathrm{~mm} \mathrm{Na}_{2} \mathrm{SO}_{4}, \mathrm{pH}$ 6.5. The concentration of this recombinant GGF2 needed to obtain half-maximal proliferation of cultured Schwann cells is $6.78 \mathrm{ng} / \mathrm{ml}$.

Immunocytochemistry. Muscles were processed for immunocytochemistry as reported previously (Trachtenberg and Thompson, 1996). AChRs were labeled with rhodamine-conjugated $\alpha$-bungarotoxin (BTx). Axons and synaptic vesicles were jointly labeled with antibodies to the $200 \mathrm{kDa}$ neurofilament protein (Developmental Studies Hybridoma Bank, Baltimore, MD; 2H3, used at 1:200), and to synaptophysin (Sigma, St. Louis, MO; S-5768, used at 1:400). An FITC-conjugated anti-mouse secondary antibody (Sigma; F-2266, used at 1:100) was used to visualize binding of these primary antibodies. SCs were labeled with anti-s100 (Dako, Carpinteria, CA; Z0311, used at 1:400) and an anti-rabbit secondary antibody conjugated to Cy5 (Jackson ImmunoResearch Labs, West Grove, PA; 111-175-144, used at 1:150). Triple labeling was accomplished by use of all three fluorochromes. Images were acquired using a Leica TCS 4D laser scanning confocal microscope. Most images were analyzed as maximal projections of the optical sections. AChR density was assayed on the basis of labeling intensity with fluorochromeconjugated BTx. Images of labeled AChRs were obtained using a Leica DMRX epifluorescence microscope with a $60 \times, 1.36$ NA objective lens. Images were captured using an integrating CCD camera and analyzed using National Institutes of Health Image software.

Physiology. Soleus muscles were dissected, pinned to Sylgard-coated dishes, and superfused with oxygenated Ringers's solution containing 2 $\mathrm{mM} \mathrm{Ca}^{2+}$ (Liley, 1956). Muscle tensions were recorded at optimal length by attaching the muscle to a sensitive strain gauge (408A, Cambridge Technology). Nerves were stimulated with supramaximal pulses $(0.2$ msec duration) using a suction electrode; direct stimulation was accomplished by $100 \mathrm{~V}$ pulses of 1-2 msec duration passed between two platinum electrodes placed on either side of the muscle belly. Intracellular recordings were made using glass microelectrodes filled with $3 \mathrm{M}$ potassium acetate (resistances of 60-100 $\mathrm{M} \Omega$ ) and a high input impedance microelectrode amplifier (WPI KS-700). Signals were digitized using a MacLab analog-to-digital converter.

Denervations and nerve transplants. Nerve resections were performed as described previously (Trachtenberg and Thompson, 1996). Nerve transplants were performed by implanting a branch of the superficial fibular nerve lacking axons to an area near the endplate zone of adult soleus muscles as described previously (Son and Thompson, 1995). Muscles were examined 2 weeks after surgery. In two of five muscles, nerve terminals were labeled jointly with anti-synaptophysin and antineurofilament. In the remaining three muscles, terminals were labeled solely with anti-synaptophysin.

\section{RESULTS}

\section{Neuregulin induces terminal Schwann cell migration and AChR dispersal in denervated neonatal muscles}

Previously, we reported that the soluble neuregulin isoform GGF2 (Marchionni et al., 1993), applied to fully denervated neonatal rat muscles, rescues terminal SCs from denervationinduced apoptosis (Trachtenberg and Thompson, 1996). Furthermore, we reported that after $3 \mathrm{~d}$ of GGF2 treatment, the position of terminal SCs in denervated muscles was affected such that they no longer fully covered synaptic sites. To investigate these changes more fully, we administered GGF2 via subcutaneous injection to rat soleus muscles for $5 \mathrm{~d}$ after their denervation on postnatal day 4 (P4). In normally innervated P9 muscles, s100positive SCs were present in the central endplate region and were

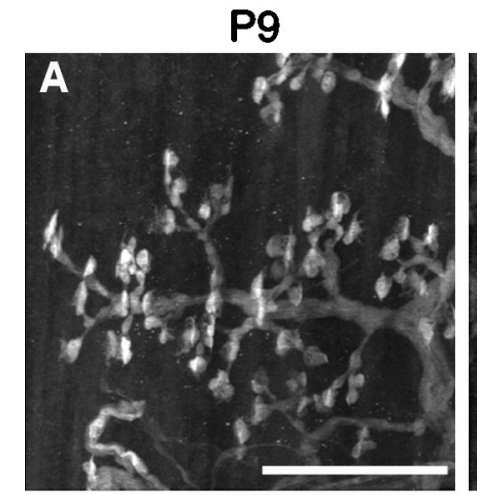

\section{Den/GGF2 P4-9}

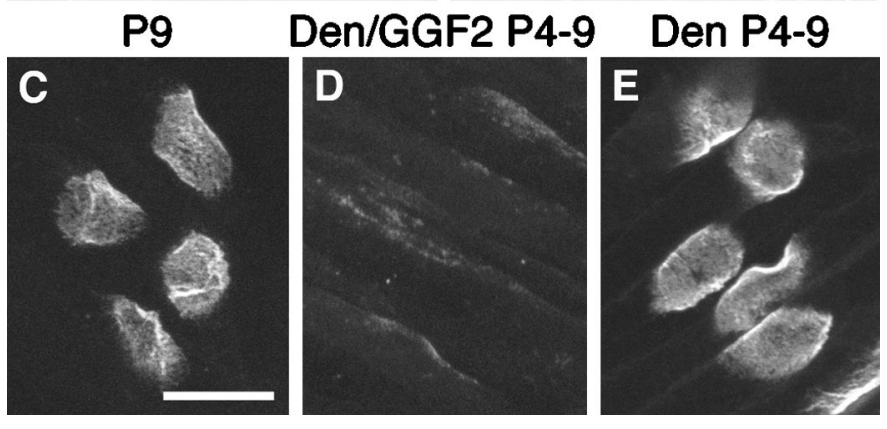

Figure 1. GGF2 induces SC migration and accelerates AChR cluster dispersal in denervated neonatal muscles. Low-magnification view of SCs, labeled with anti-s100, in $(A)$ a normally innervated $\mathrm{P} 9$ muscle and $(B)$ a $\mathrm{P} 9$ soleus muscle denervated on $\mathrm{P} 4$ and exposed daily for $5 \mathrm{~d}$ to exogenous GGF2. Terminal SCs in the GGF2-treated, denervated muscle were no longer clustered over endplates as in the control muscle but had migrated and extended processes. The processes grew primarily in an orientation parallel to the muscle fibers. Muscle fibers extend from top to bottom in $A$ and $B$. $C-E$, AChR plaques labeled with rhodamine-conjugated BTx in a normally innervated $\mathrm{P} 9$ soleus muscle $(C)$, a $\mathrm{P} 9$ soleus muscle denervated on P4 and exposed daily for $5 \mathrm{~d}$ to exogenous GGF2 $(D)$, and a P9 soleus muscle denervated on $\mathrm{P} 4$ and examined $5 \mathrm{~d}$ later $(E)$. Muscle fibers extend diagonally in $C-E$. Scale bar (shown in $A$ ): $100 \mu \mathrm{m}$; (shown in $C$ ): $20 \mu \mathrm{m}$.

clustered above motor nerve terminals (Fig. 1A); however, in denervated muscles exposed to GGF2, SCs appeared to have migrated away from synaptic sites (Fig. $1 B$ ). These migrating SCs had extended processes that were oriented primarily parallel to the muscle fibers, as has been reported for reactive SCs in denervated or paralyzed adult muscles (Reynolds and Woolf, 1992; Son and Thompson, 1995). Additionally, there appeared to be a larger number of SCs in GGF2-treated than in control muscles, suggesting that GGF2 had induced proliferation of these cells. The extent of this proliferation was difficult to assess, because SCs had migrated some distance from the endplates and the processes of the cells overlapped extensively. Counts of the cells in microscope fields near the endplate zone (as in Fig. $1 A, B$ ) suggest an increase in SC number of at least $30 \%$. When the period of GGF2 treatment was extended to $7 \mathrm{~d}$, SCs were observed at even greater distances from the endplate zone, suggesting that GGF2-treatment had induced these cells to migrate toward the tendons at each end of the muscle (data not shown). These results are consistent with previous reports demonstrating that neuregulin induces Schwann cell migration and proliferation in vitro (Morrissey et al., 1995; Mahanthappa et al., 1996). As reported previously (Trachtenberg and Thompson, 1996), terminal SCs had died and thus were absent from muscles denervated on P4 and exposed to vehicle lacking GGF2 (data not shown).

Labeling with fluorochrome-conjugated BTx revealed that 
Table 1. Muscle tensions

\begin{tabular}{lllll} 
& \multicolumn{2}{l}{ GGF2-treated soleus } & & $\begin{array}{l}\text { Contralateral } \\
\text { soleus }\end{array}$ \\
\cline { 2 - 3 } Animal & $\begin{array}{l}\text { Nerve tension } \\
(\mathrm{gm})\end{array}$ & $\begin{array}{l}\text { Direct tension } \\
(\mathrm{gm})\end{array}$ & $\begin{array}{l}\text { Nerve tension } \\
(\mathrm{gm})\end{array}$ \\
\hline GGF2 P4-9 \#1 & 0 & 0.36 & 1.25 \\
GGF2 P4-9 \#2 & 0 & 0.33 & 1.48 \\
GGF2 P4-9 \#3 & 0 & na & 1.41 \\
GGF2 P4-9 \#4 & 0 & 0.72 & na \\
GGF2 P4-9 \#5 & 0 & 1.50 & 1.78 \\
GGF2 P11-16 \#1 & 0.17 & na & 2.67 \\
GGF2 P11-16 \#2 & 0.20 & na & 3.27 \\
GGF2 P11-16 \#3 & 1.00 & na & 2.50 \\
GGF2 P11-16 \#4 & 0.75 & na & 3.38 \\
GGF2 P11-16 \#5 & 1.18 & 2.63 & 3.15 \\
GGF2 P11-16 \#6 & 0.64 & 2.38 & 3.45 \\
GGF2 P11-16 \#7 & 0.32 & 2.31 & 3.38 \\
\hline
\end{tabular}

AChRs in denervated muscles were also altered by GGF2 treatment. Organized into well defined clusters in normally innervated muscles (Fig. 1C), AChRs in denervated, GGF2-treated muscles (Fig. $1 D$ ) were poorly clustered, occupied an enlarged area of the muscle fiber membrane, and were markedly reduced in staining intensity compared with receptor plaques in control muscles. Similar disruptions in AChR clusters have been reported in muscles denervated on P0 and examined after 1 week of denervation (Slater, 1982). To examine whether the changes in AChR distribution were a response to denervation or to GGF2 treatment, we denervated muscles on P4 and exposed them daily for $5 \mathrm{~d}$ to vehicle lacking GGF2. AChRs in these muscles remained clustered in well defined although somewhat enlarged plaques and appeared qualitatively to be as intensely labeled as endplates in normally innervated muscles of the same age (Fig. 1E), even when the intensity of labeling was assessed at constant camera gain. Thus, exogenous GGF2 appears to accelerate the onset of denervation-induced changes in the organization of AChRs.

We next examined whether similar changes in the organization of SCs and AChRs could be induced in normally innervated muscles, and if so, how these changes influenced the normal pattern of innervation.

\section{Neuregulin induces synaptic loss and axonal sprouting in innervated neonatal muscles.}

To investigate the effect of exogenous GGF2 on synaptic organization in normally innervated neonatal muscles, GGF2 was injected subcutaneously once daily into the right crus beginning at P4. On P9, GGF2-treated muscles and control muscles (muscles contralateral to the GGF2 injection, and muscles from animals injected with vehicle or left untreated) were examined physiologically and morphologically. Soleus muscles exposed to GGF2 ( $n=$ 5) showed pronounced physiological deficits in their innervation: stimulation of the muscle nerve failed to produce any measurable twitch tension (Table 1). Direct stimulation of four of these muscles showed that their muscle fibers could generate contractions (Table 1), suggesting that the absence of nerve-evoked twitches was largely attributable to deficiencies in the ability of the nerve to excite the muscle fibers. These deficits were not seen in muscles from any of the control groups. The physiology of muscles contralateral to those in the injected leg was indistin-
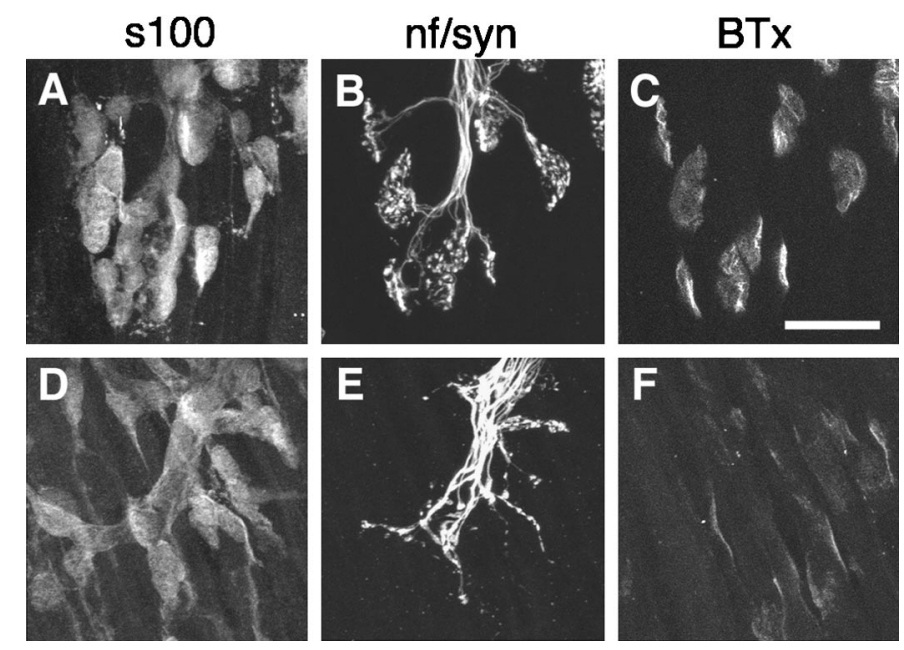

Figure 2. GGF2 induces synaptic loss from innervated neonatal muscles. $A-C$, Neuromuscular junctions in a normal P9 soleus muscle and $(D-F)$ a P9 soleus muscle exposed to exogenous GGF2 for $5 \mathrm{~d}$. Junctions were triple-labeled with anti-s100 to label SCs $(A, D)$, anti-neurofilament and anti-synaptophysin to label motor axons and their terminals $(B, E)$, and BTx to label AChRs $(C, F)$. At normally innervated junctions, terminal SCs $(A)$ were clustered over nerve terminal arborizations $(B)$ that precisely juxtaposed AChR-rich regions in the postsynaptic muscle membrane $(C)$. At junctions exposed to exogenous GGF2 for $5 \mathrm{~d}$, terminal SCs $(D)$ were poorly organized and had extended processes; nerve terminal arborizations were absent, although motor axons in the intramuscular nerves appeared unperturbed $(E)$. AChRs were no longer clustered into well defined plaques $(F)$. Scale bar, $20 \mu \mathrm{m}$.

guishable from that of muscles taken from animals that received vehicle (data not shown). Thus, the effects of the injected GGF2 were confined to muscles near the site of injection.

Immunostaining of GGF2-treated muscles revealed striking changes in their synaptic organization. In control muscles, motor axons ramified to form nerve terminal arbors shortly after branching from the intramuscular nerves (Figs. $2 B, 3 A$ ). Each nerve terminal innervated an AChR-rich area of the muscle fiber membrane (Fig. 2C) and was covered by clusters of terminal SCs (Fig. $2 A$ ). In GGF2-treated muscles, motor axons were present in the intramuscular nerves, but immunostaining for terminal arborizations was absent (Fig. 2E), suggesting that nerve terminal branches had been retracted. AChRs and SCs in these muscles were affected as in denervated muscles exposed to the same regimen of GGF2 treatment. AChR clusters (Fig. $2 F$ ) were no longer covered by nerve terminal branches, lacked well defined borders, and labeled weakly with BTx. SCs (Fig. 2D) were associated with the endings of motor axons but were largely absent from former synaptic sites (defined by the poorly organized AChR clusters). As in denervated, GGF2-treated muscles, we observed an abundance of SCs in extrajunctional regions of these muscles that were not associated with axons (aneural SCs), suggesting that GGF2 can induce SC migration and proliferation even when motor axons are present. The morphology of junctions of muscles contralateral to the injection was indistinguishable from that of vehicle-treated animals, suggesting the absence of any systemic effect.

Changes in the organization of pre- and postsynaptic components of neuromuscular junctions became more pronounced as the duration of GGF2 treatment was extended. In muscles exposed to GGF2 for $10 \mathrm{~d}$ (P4-P14), motor axons no longer terminated in a central endplate band as they did in control muscles 

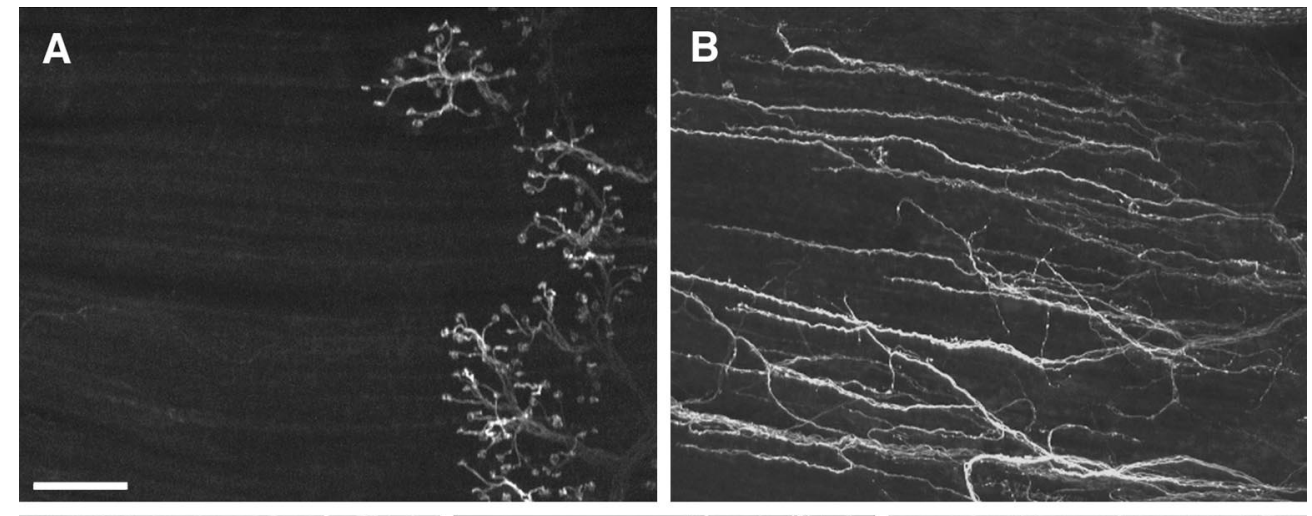

Figure 3. Neonatal muscles exposed to GGF2 for $10 \mathrm{~d}$ are characterized by robust axonal sprouting. Normally innervated $(A)$ and GGF2-treated P14 soleus muscles $(B-E)$. Muscles were labeled as in Figure 2. $A$, In normally innervated muscles, motor axons ramify shortly after branching from intramuscular nerves, establishing an endplate zone across the middle of the muscle. $B$, In a P14 muscle exposed to exogenous GGF2 for the previous $10 \mathrm{~d}$, motor axons grew hundreds of micrometers throughout the muscle. $C$, SCs were closely associated with axons in these muscles and had extended processes (arrow). D, Rudimentary nerve terminals were present (arrowheads), although they lacked the arbors that characterize normal terminals. $E$, AChR clusters were associated with some axon terminations (arrowheads in $E)$, although multiple, aneural AChR clusters were present as well (arrows in $D$ and $E$ ). Scale bar (shown in $A$ ): 100 $\mu \mathrm{m}$; (shown in $C$ ): $50 \mu \mathrm{m}$.
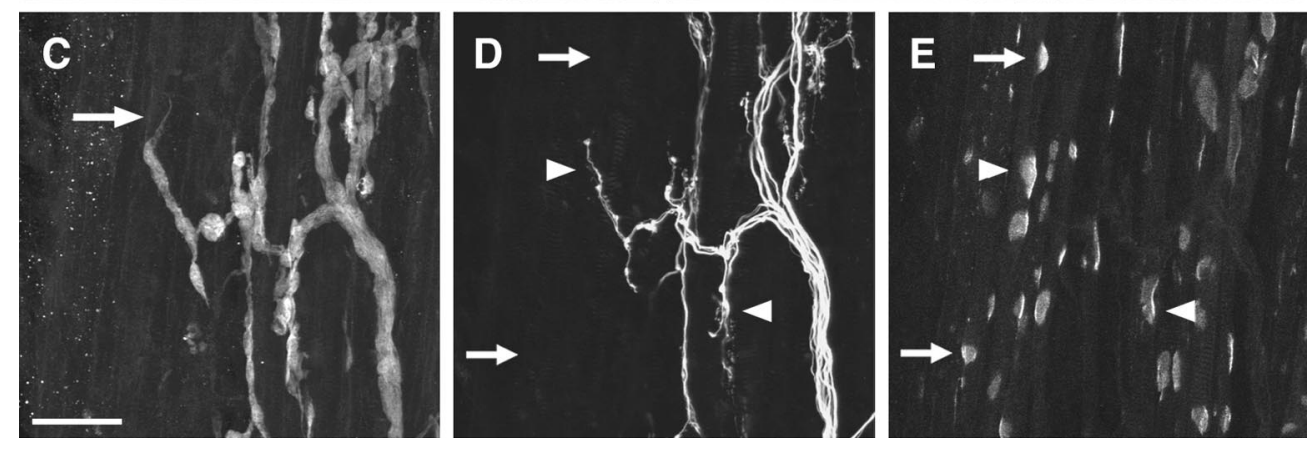

(Fig. 3A). Instead, motor axons had grown long distances throughout GGF2-treated muscles in an orientation chiefly parallel to the long axis of the muscle fibers (Fig. $3 B$ ), and only rudimentary nerve terminal specializations could be identified in the vicinity of the former endplate zone (Fig. 3D). SCs were consistently associated with axons (Fig. 3C), and their processes were either leading (Fig. $3 C, D$ ) or coextensive with the tips of the growing axons. SCs that were not associated with axons were absent from these muscles, suggesting that the large number of aneural SCs in muscles exposed to GGF2 for only $5 \mathrm{~d}$ had either disappeared or fasciculated with axons. Well organized, brightly labeled AChR clusters were present at multiple sites along muscle fibers (Fig. 3E). These clusters likely result from the denervation induced by GGF2, because extrajunctional clusters are known to occur in denervated mammalian muscles (Ko et al., 1977) and similar clusters were observed in denervated neonatal muscles not exposed to GGF2. Within the region of the former endplate zone, AChR clusters were often associated with rudimentary nerve terminals (Fig. 3D,E, arrowheads), although in most cases the shapes of the receptor plaques did not match the profile of the nerve processes apposing them. Nerve stimulation in these muscles evoked very weak contractions $(<2 \%$ of the contralateral muscle), showing that few effective synapses were present.

In summary, application of GGF2 to normally innervated neonatal muscles induces terminal SCs to migrate away from synaptic sites and motor axons to retract their terminal arborizations, and it accelerates the dispersal of AChRs from functionally denervated endplates. Subsequent to these changes, motor axons grow robustly along SC pathways, and although clusters of AChRs appear along the muscle fibers, there is little synaptogenesis, in contrast to what would normally be expected with motor axons present in denervated muscle (Jansen et al., 1973).

Similar, although less robust, changes in synaptic organization were also induced by exogenous neuregulin in muscles from P11 rats. Soleus muscles exposed to GGF2 from P11-P16 produced $20 \pm 14 \%$ of the nerve-evoked twitch tensions of control muscles $(n=7)$. As with $\mathrm{P} 4$ muscles exposed to GGF2, this weakening appeared to be largely attributable to synaptic deficits, because direct stimulation of these muscles $(n=3)$ produced twitches two to seven times stronger than nerve-evoked twitches; however, the contractions elicited by direct stimulation were only $74 \pm 8 \%$ as strong as those of the contralateral muscles (Table 1). To examine whether this deficit in direct tension could be explained by fiber atrophy expected to result from GGF2-induced denervation, we measured the direct tensions of soleus muscles that had been denervated by sciatic nerve resection for $3 \mathrm{~d}$ beginning on P13. These denervated muscles had direct tensions that were $69 \pm 9 \%$ of the innervated, contralateral muscles, suggesting that the weakening of GGF2-treated muscles resulted from loss of functional innervation rather than GGF2-induced changes in muscle fiber properties. Given that muscles of this age are slightly larger and more mature, and thus more readily examined physiologically and morphologically, we focused on this age group for a more thorough analysis of the neuregulin-induced changes in synaptic organization.

\section{Nerve terminal loss is progressive and precedes changes in AChR density}

Neuregulin, applied to developing muscles, induces nerve terminals to retract from contact with underlying muscle fibers and terminal SCs to migrate off of synaptic sites, and it destabilizes existing AChR clusters. AChRs are thought to critically modulate the signaling interactions between nerve and muscle that influence the stabilization or loss of nerve terminal branches. Before axon withdrawal from poly-innervated endplates undergoing synapse elimination, there is a subjacent loss of AChRs (Rich and Lichtman, 1989a; Balice-Gordon and Lichtman, 1993), and at singly innervated, adult junctions the spatially restricted blockade of AChRs at an endplate results in the loss of these receptors and withdrawal of overlying nerve terminal branches (Balice-Gordon and Lichtman, 1994). AChR loss from developing junctions can be detected morphologically, as a decrease in BTx labeling inten- 
A

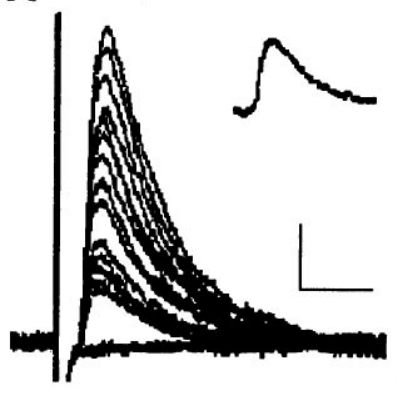

B

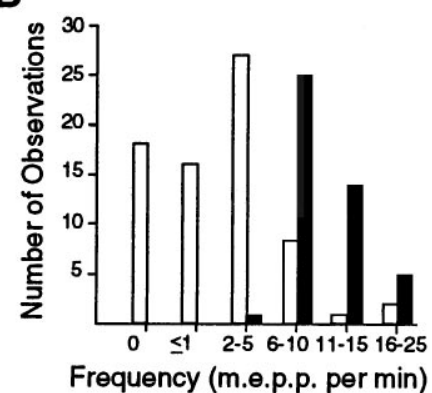

P16

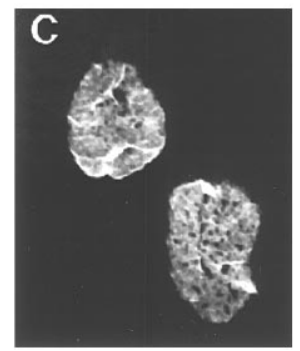

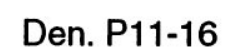
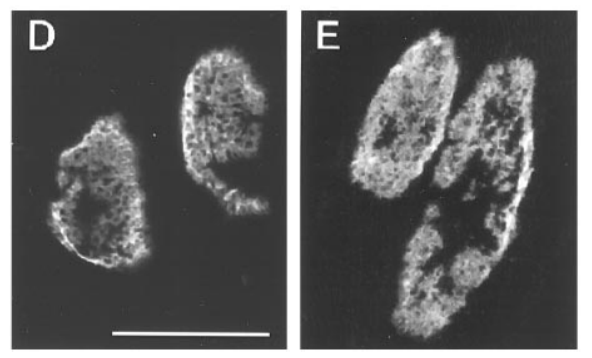

Figure 4. Synaptic efficacy is decreased in GGF2-treated muscles before changes in postsynaptic AChR density. $A$, Superimposed intracellular records of epps obtained during nerve stimulation in a P16 muscle treated with GGF2 for the previous $5 \mathrm{~d}$. The epps were subthreshold and frequently failed. A spontaneous potential (mepp) recorded from the same fiber is shown in the inset. Calibration: $4 \mathrm{mV}, 10 \mathrm{msec} . B$, Mepp frequency in GGF2-treated muscles (open bars) was greatly reduced relative to controls ( filled bars). Fibers in which there were 0 mepps/min were counted only if we could elicit epps with fast rise times on soleus nerve stimulation, indicating that we were recording from the vicinity of the endplate. $C, \mathrm{BTx}$ labeled AChR clusters at endplates in a P16 control muscle, $(D)$ a P16 muscle treated with GGF2 for the previous $5 \mathrm{~d}$, and $(E)$ a P16 muscle that had been denervated for 5 preceding days. Scale bar, $20 \mu \mathrm{m}$.

sity (Balice-Gordon and Lichtman, 1993), and physiologically, by the presence of small-amplitude miniature endplate potentials (mepps) that grade into the recording noise (Colman et al., 1997). To determine whether AChR loss precedes the retraction of nerve terminal branches in GGF2-treated muscles, we examined the postsynaptic response to neurotransmission by recording intracellularly from muscle fibers. In the majority of fibers in GGF2-treated muscles (70 fibers in four muscles), nerve stimulation failed to evoke action potentials or did so only intermittently, revealing underlying subthreshold epps. Additionally, there were a number of fibers in which no synaptic response at all could be elicited by nerve stimulation. In two muscles that produced the weakest nerve-evoked twitch tensions (10 and $18 \%$ of control twitch tensions), we recorded from 29 fibers that responded to nerve stimulation with subthreshold epps and occasional action potentials. The remainder of the fibers penetrated in these two muscles $(>90)$ showed no response at all. Of the 29 fibers that responded to nerve stimulation, six produced small amplitude epps and periodically failed completely (Fig. $4 A$ ); these synapses showed the same type of quantal variation seen in normal muscles bathed in low calcium, high magnesium Ringer's solution (Del Castillo and Katz, 1954). Comparison of the increment in epp size in these six fibers with the size of their spontaneous mepps (Fig. 4A) and computation of the average quantal size computed by the method of failures (Del Castillo and Katz,

1954) showed that the remaining transmission was quantal in nature. Small-amplitude evoked or spontaneous potentials that graded into the recording noise were not seen in any of the fibers from which we recorded. Mepp frequency, however, was reduced in GGF2-treated muscles compared with control muscles (3 mepps/min GGF2 vs 11 mepps/min control) (Fig. 4B). Within GGF2-treated muscles, mepps were less frequent in fibers that responded with subthreshold epps to nerve stimulation than in fibers that produced action potentials, suggesting that mepp frequency and evoked synaptic transmission declined in parallel as the nerve terminal lost branches and transmitter release sites (see below). Furthermore, mepp amplitude in fibers with subthreshold epps was increased compared with either vehicle-treated or untreated control muscles $(2.4 \pm 0.8 \mathrm{mV}$ in 11 GGF2-treated fibers vs $2.0 \pm 0.5 \mathrm{mV}$ in 10 control fibers; vehicle-treated and untreated muscles showed no significant differences in mepp frequency or amplitude). It is unclear from this analysis whether the increase in mepp amplitude is a result of presynaptic changes in vesicle packaging, postsynaptic increases in sensitivity, decreased acetylcholinesterase activity, or increased input resistance in fibers that atrophy after the loss of suprathreshold inputs. These results suggest, however, that GGF2 induces nerve terminal loss without appreciably changing AChR density.

Consistent with the physiological data, synaptophysin staining of nerve terminals in muscles treated with GGF2 for $5 \mathrm{~d}$ between P11 and P16 revealed that nerve terminal branches had been lost from the majority of junctions examined (381 of 534 endplates examined in five muscles) (Fig. $5 F, H$ ). The extent of terminal loss (determined by the presence of AChRs in regions of an endplate that were not overlain by nerve terminal branches) varied. Some nerve terminals had lost a small portion of their arborization, whereas others had lost their entire arborization and appeared like retraction bulbs (Riley, 1981; Balice-Gordon et al., 1993). AChR clusters at disrupted synapses (Fig. 4D) were expanded in size, and their borders were less well defined than AChR clusters in control muscles (Fig. $4 C$ ), although these changes likely were a response to the loss of suprathreshold input rather than a direct effect of the GGF2 on AChR clustering in muscles of this age, because similar changes were seen in fully denervated, untreated muscles from age-matched litter mates (Fig. 4E) (Slater, 1982). A quantitative analysis of BTx labeling intensity (using a CCD camera to analyze gray scale values of pixels within the images achieved at constant gain and integration time) revealed that although AChR clusters were slightly less intense in GGF2treated than in control muscles (93-98\% of control values), these differences were not statistically significant. Thus, in contrast to GGF2 treatment at P4, treatment at P11 does not appear to affect the density of postsynaptic AChRs; the reason for this age-related difference is obscure. Variations in the intensity of AChR labeling were observed across individual endplates after treatment with GGF2 commencing at P11. Regions underneath some of the remaining nerve terminals appeared more intensely labeled than other regions lacking nerve terminal staining (e.g., Fig. 5G, top left portion of the junction). In other cases (e.g., bottom left half of the junction in Fig. $5 K$ ), however, regions underlying the nerve terminal were as dimly labeled as any other region of the junction lacking such terminal labeling. In any case, the pattern of AChR distribution could not be used to predict reliably which regions of the endplate were still apposed by immunostained terminal branches (Fig. $5 F-H$ ).

To examine the progression of synaptic changes after GGF2 administration, we examined muscles $1-2 \mathrm{~d}$ after GGF2 ad- 


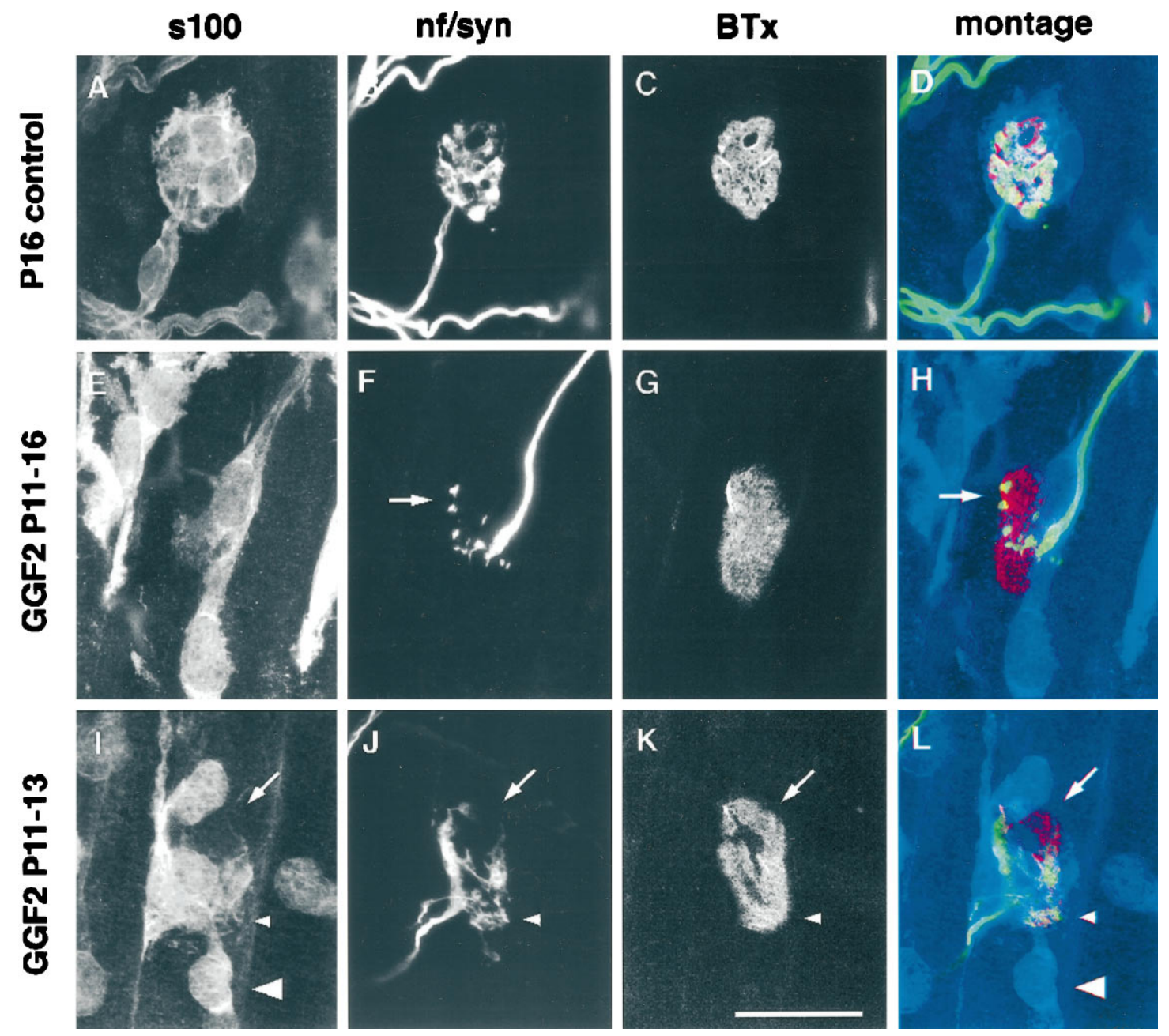

Figure 5. Changes in terminal SCs correlate with the loss of nerve terminal branches from GGF2-treated muscles. Junctions were triple-labeled as in Figure 2. In the color montages $(D, H, L)$, anti-s100 is displayed in blue, anti-neurofilament and anti-synaptophysin are displayed in green, and BTx is displayed in red. $A-D$, A junction from a P16 control muscle. Note in $D$ the precise overlap of terminal SCs $(A)$, nerve terminal branches $(B)$, and AChRs (C). $E-H$, A junction from a P16 soleus muscle treated with GGF2 for $5 \mathrm{~d}$. Terminal SCs at this junction $(E, H)$ appear to have migrated off the endplate. Nerve terminal branches have been lost from most of the areas of this endplate that are no longer covered by terminal SCs. Terminal branches that remained in the absence of SC coverage (arrows, $F, H)$ had a punctate labeling pattern and were probably in the process of being retracted. AChRs $(G$, $H)$ at this endplate remained well clustered, although portions were no longer covered by either nerve terminal branches or terminal SCs. $I-L$, A junction from a P13 soleus muscle treated with GGF2 for $2 \mathrm{~d}$. At this junction two terminal SCs have migrated off the endplate (I, $L)$. The loss of coverage by the terminal SC at the top of the junction (apparently by movement of the upper SC) is correlated with an absence of neurofilament/synaptophysin staining in this area of the endplate, although not with a decreased staining intensity of the underlying AChRs (arrow, $K, L)$. At the bottom of this junction a terminal SC has migrated off the endplate, leaving only a thin veil covering the underlying terminal (I, L, large arrowhead). This SC change is not associated with any change in the alignment of nerve terminal branches and AChRs (small arrowhead, $J-L$ ). Scale bar, $20 \mu \mathrm{m}$.

ministration. No changes in twitch tension between GGF2treated and contralateral muscles were observed after only $1 \mathrm{~d}$ of treatment, nor were there any signs of significant synaptic disruption (Table 2), decreased AChR density (Table 3), or alterations in muscle fiber diameter, a second measure of possible postsynaptic changes induced by GGF2 (Table 4). In muscles examined after only $2 \mathrm{~d}$ of GGF2 exposure (P11-P13), the synaptic changes were more extensive than those seen after $1 \mathrm{~d}$, although less than after $5 \mathrm{~d}$ of exposure. Of 124 endplates viewed en face, 21 displayed signs of nerve terminal loss (Fig. $5 I-L$, Table 2). Anti-synaptophysin staining was qualitatively less dense at another 46 junctions in these muscles (Table 2). AChR density, determined on the basis of BTx labeling intensity, was not statistically different between these groups and endplates in contralateral, control muscles treated with vehicle alone (Table 3). Additionally, although we observed slight variations in AChR density across endplates from which nerve terminal staining had been lost, these changes in receptor density could not be used to predict whether an overlying nerve terminal branch was present or absent (see preceding paragraph). Muscle fiber diameters were also not consistently different between GGF2-treated and control muscles. In one muscle pair, fiber diameter was significantly larger in the GGF2-treated muscle relative to its contralateral control; however, in the remaining two muscle pairs there were no statistical differences in fiber diameter between GGF2-treated and contralateral control muscles (Table 4).

On the basis of the data presented above, we suggest that nerve terminal retraction from GGF2-treated muscles precedes changes in AChR density and muscle fiber diameter. 

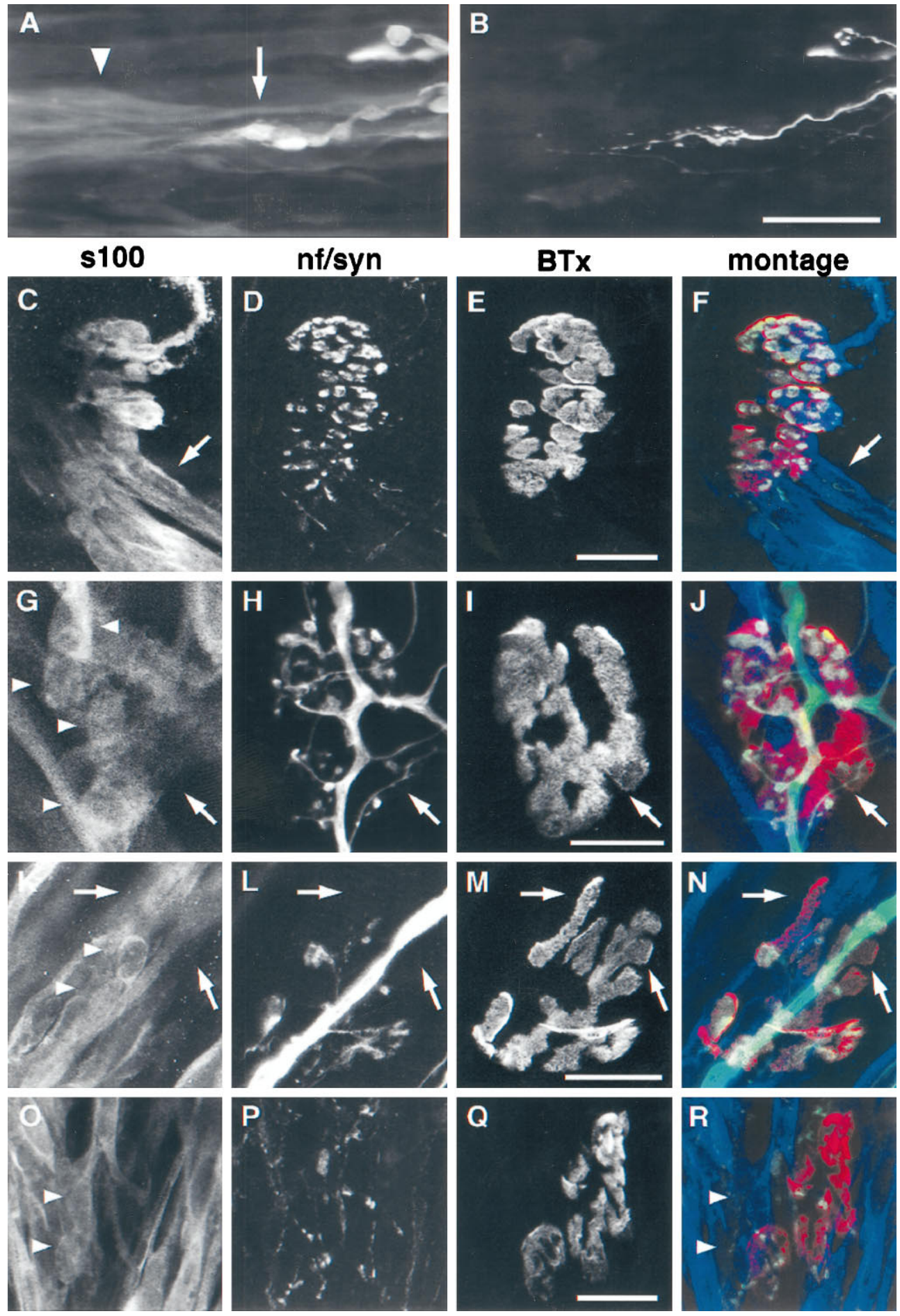
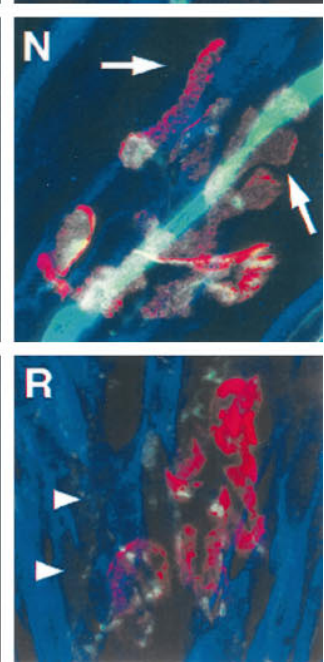

Figure 6. Reactive SCs growing from transplanted nerves induce the retraction of portions of nerve terminals in host muscles. A, SCs (arrowhead), labeled with anti-s100, have grown from a transplanted foreign nerve and contacted terminal SCs (arrow) at a junction in the host muscle. The host terminal SCs are more intensely labeled with anti-s100 and are themselves extending processes. One of the host SC somata appears displaced somewhat from the endplate. $B$, The nerve terminal at this junction is poorly organized and has sprouted along the transplanted SCs and the processes growing from the host $\mathrm{SCs}$. $C-R$, Highmagnification images of three junctions affected by the transplanted, foreign SCs. Junctions were triple-labeled as in Figure 2; color montages as in Figure 5. Antisynaptophysin alone was used to label the nerve terminal in $D, F$ and $P, R . C-F$, An endplate that has been contacted by transplanted SCs for only a short time. Transplanted SCs (arrow in $C, F$ ) have contacted the lower half of this junction; synaptophysin $(D)$ staining density is decreased in the area of contact, leaving portions of the underlying AChR cluster $(E)$ uncovered. Nerve terminal branches in the areas of this junction that have not been contacted by the transplanted SCs remain well organized. $G-J, K-N, O-R$, Three endplates that have been overgrown by transplanted SCs. SC bodies (arrowheads in $G, K, O$ ) are poorly organized at these endplates. Areas of these endplates no longer apposed by nerve terminal branches (identified with arrows in $H, J, L, N)$ are devoid of SC somata. Scale bars: $A, B, 50 \mu \mathrm{m} ; C-R, 20 \mu \mathrm{m}$.

\section{Synaptic loss is accompanied by alterations in terminal Schwann cells}

Changes in the morphology and position of Schwann cells have been correlated with synapse elimination and nerve terminal remodeling in the peripheral nervous system (Matthews and Nelson, 1975; Riley, 1981; Pomeroy and Purves, 1988; Noakes et al., 1995). As such, we examined whether the changes in terminal SCs in GGF2-treated muscles were correlated with the retraction of nerve terminal branches. In muscles treated with exogenous GGF2 from P11 through P16, there were pronounced changes in the organization, position, and morphology of terminal SCs. At all junctions examined (534 junctions in five muscles), including those at which a precise alignment between nerve terminal branches and AChRs was maintained, terminal SCs were altered; however, changes in terminal SC morphology and position were most severe at junctions from which nerve terminal branches had been lost. At the majority of these junctions, terminal SCs no longer covered the entire endplate as they do in control junctions (Fig. 5A-D). Rather, terminal SCs (Fig. 5E,H) appeared to have migrated off synaptic sites, leaving large portions of the underlying AChRs uncovered (Fig. 5G,H). Nerve terminal branches (Fig. $5 F, H)$ were correspondingly absent from these denuded regions, 
Table 2. Alterations in the morphology and apposition of nerve terminals (NTs) and terminal SCs (TSCs) resulting from GGF2 treatment from P11 to $\mathrm{P} 12$ or P13

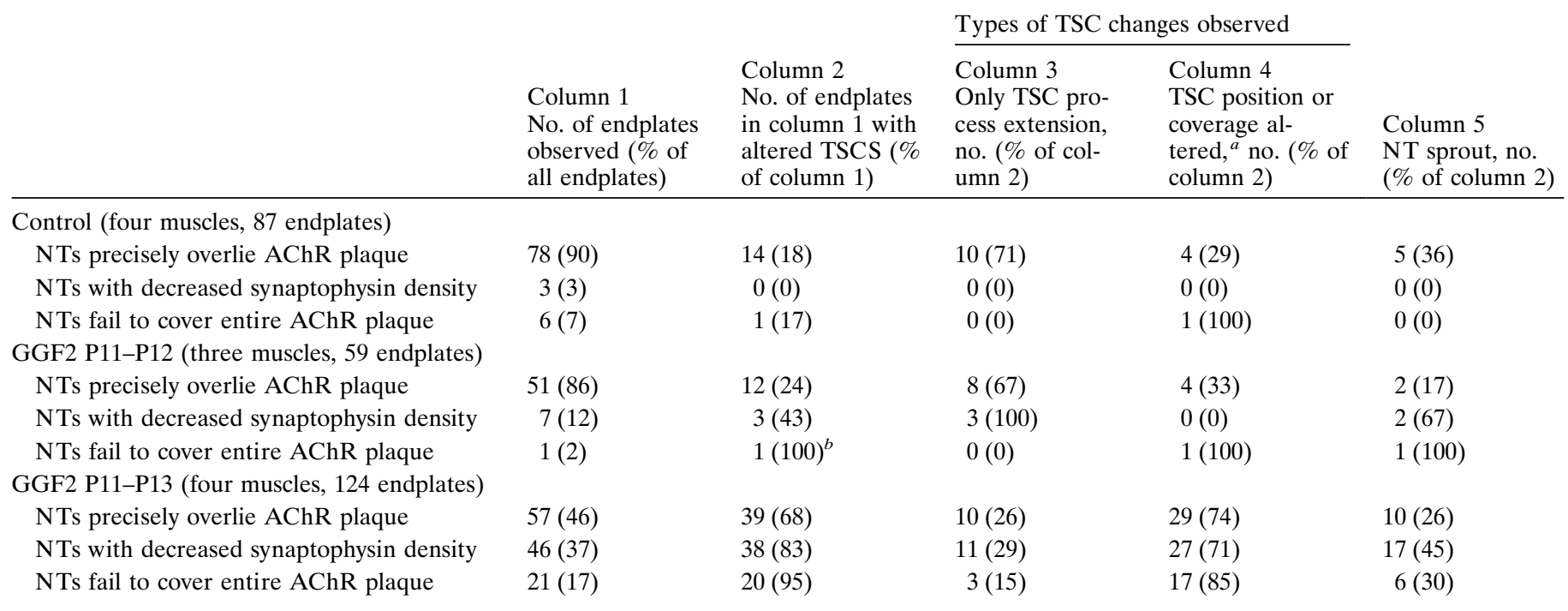

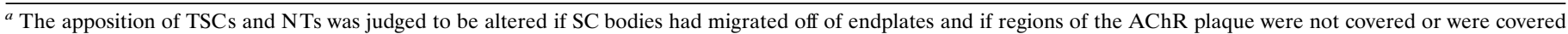
by only a thin veil of SC membrane. All NT sprouts were observed to be associated with processes of the TSC.

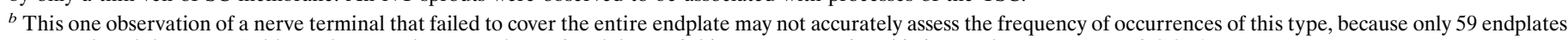
were analyzed; however, $1 \mathrm{~d}$ later there are large numbers of endplates of this type, suggesting this is a real consequence of GGF2 treatment.

\section{Table 3. AChR staining intensity}

\begin{tabular}{ll} 
& Average gray value \\
\hline GGF2 P11-P12 (three muscles) & $117 \pm 22.7(59)$ \\
P12 contralateral control (three muscles) & $118 \pm 22.7(56)$ \\
GGF2 P11-P13 (four muscles) & \\
$\quad$ NTs that precisely overlie AChR plaque & $141 \pm 22 \quad(56)$ \\
NTs with decreased synaptophysin density & $144 \pm 19 \quad(46)$ \\
NTs that fail to cover entire AChR plaque & $137 \pm 21 \quad(21)$ \\
P13 contralateral control (two muscles) & $142 \pm 21 \quad(62)$
\end{tabular}

The decreased gray value of the top two rows relative to the bottom four rows does not indicate an actual increase in receptor density in the top muscles but is attributable to different camera gains. No statistically significant differences were seen between any of the groups. NT, Nerve terminal. Gray value: $0=$ white, $256=$ black. Values are mean \pm SD (number of observations).

although in some cases thin, faintly labeled remnants of terminal branches were present where SCs were clearly absent (arrow, Fig. $5 F, H)$. At some junctions, nerve terminals were absent from areas of the endplate that were covered by SCs; however, there is some uncertainty about whether the SCs present at these junctions were those that originally covered these sites, because we observed a number of cases in which SCs had migrated from the endoneurial tubes leading to endplates.

Changes in the position and morphology of SCs were also examined in the muscles that had been exposed to GGF2 for shorter periods (Table 2). As discussed above for nerve terminals, changes in SCs after 1-2 d of treatment were less dramatic than after $5 \mathrm{~d}$ of treatment; however, a higher percentage of junctions had obvious alterations in SCs than had alterations in their nerve terminals. For example, after $1 \mathrm{~d}$ of treatment, $13 \%(8 / 59)$ of the junctions had altered nerve terminals but $27 \%(16 / 59)$ had altered terminal SCs; after 2 d of treatment, 54\% (67/124) of junctions had altered nerve terminals but $79 \%$ (97/124) had altered terminal SCs. These numbers argue that a large fraction of the junctions undergo changes in their SCs before changes in their nerve terminals. Indeed, in muscles exposed to GGF2 from P11-P13, terminal SCs were altered in their morphology or had migrated off endplates, leaving AChR-dense regions uncovered or covered by only a thin SC veil at $95 \%$ (20/21) of the junctions that had lost portions of their terminal arbors (Fig. 5I-L, Table 2). It should be noted, however, that after 1 and $2 \mathrm{~d}$ of GGF2 treatment, 4 of 7 and 8 of 46 junctions, respectively, had suffered a decrease in the density of their synaptophysin labeling, although there were no obvious changes in their SCs (Table 2). This finding suggests that either the decrease in synaptophysin density results from GGF2induced changes in muscle fibers rather than SCs, or it results from GGF2-induced changes in SCs that are not detected by immunostaining (e.g., alterations in SC-axon signaling interactions; see Discussion). Although the resolution of the exact temporal sequence of changes in SCs and nerve terminals will require further investigation, the data presented here suggest that nerve terminal retraction in GGF2-treated muscles precedes postsynaptic changes in AChR density or muscle fiber diameter but is commonly correlated with changes in the apposition of terminal SCs and nerve terminals as the SCs begin to migrate.

\section{Transplanted Schwann cells can induce the retraction of nerve terminal branches in the absence of exogenous GGF2}

GGF2 is known to act on both SCs and muscle fibers. Therefore, it is possible that the withdrawal of nerve terminal branches results from GGF2-induced changes in muscle-derived retrograde signals rather than changes in terminal SCs. To determine whether alterations of terminal SC position and morphology play a causal role in nerve terminal retraction, we examined the fate of nerve terminals at junctions from which terminal SC migration was induced by means other than the application of exogenous GGF2. SCs at the cut ends of a nerve extend processes and migrate (Son and Thompson, 1995), much as do SCs in GGF2treated, developing muscles. Thus, we transplanted previously resected foreign nerves near the endplate region of normally innervated adult host muscles and examined whether reactive 


\begin{tabular}{llll}
\hline $\begin{array}{l}\text { Table 4. Muscle fiber diameter } \\
\text { Condition }\end{array}$ & Animal \#1 & Animal \#2 & Animal \#3 \\
\hline GGF2 P11-P12 & $24.8 \pm 5.6 \mu \mathrm{m} \mathrm{(30)}$ & $26.5 \pm 5.4 \mu \mathrm{m}(33)$ & $25.1 \pm 6.2 \mu \mathrm{m}(55)$ \\
P12 contralateral control & $26.3 \pm 6.5 \mu \mathrm{m} \mathrm{(56)}$ & $24.7 \pm 5.1 \mu \mathrm{m} \mathrm{(46)}$ & $26.8 \pm 4.3 \mu \mathrm{m}(36)$ \\
GGF2 P11-P13 & $16.6 \pm 3 \mu \mathrm{m} \mathrm{(29)*}$ & $14.4 \pm 2.8 \mu \mathrm{m} \mathrm{(47)}$ & $15.1 \pm 3.0 \mu \mathrm{m}(53)$ \\
P13 contralateral control & $14.0 \pm 2.5 \mu \mathrm{m} \mathrm{(75)}$ & $14.4 \pm 2.7 \mu \mathrm{m} \mathrm{(56)}$ & $14.6 \pm 3.9 \mu \mathrm{m}(45)$
\end{tabular}

Muscle fiber diameter was measured from DIC images taken of the most superficial muscle fibers in a muscle. Values reported are mean $\pm \mathrm{SD}$ (number of observations). ${ }^{*} p<0.01$ (Student's $t$ test).

SCs growing from such transplants could induce the retraction of nerve terminal branches from endplates that they contacted.

In 5 of 14 transplants, reactive SCs grew into a region of the endplate band and contacted host nerve terminals and their associated terminal SCs. In one of these muscles, transplanted SCs had only begun to infiltrate the endplate band and interact with host nerve terminals and terminal SCs. Some of the terminal SCs in this muscle were affected by their interactions with the transplanted SCs and appeared to be in the process of extending processes and migrating off synaptic sites (Fig. $6 A, B$ ) in a manner similar to that observed in GGF2-treated, developing muscles. In the remaining muscles, SCs growing from transplants had more thoroughly infiltrated the endplate region of their host muscles. In these muscles, 14 of 33 junctions contacted by transplanted SCs displayed signs of nerve terminal loss noted by the presence of AChRs unapposed by nerve terminal branches in portions of an endplate (Fig. $6 C-R$ ). SC somata (arrowheads, Fig. $6 G, K, O$ ) could no longer be identified over the regions of these endplates that had lost nerve terminal branches, demonstrating that here, as at disrupted synapses in GGF2-treated muscles, the retraction of nerve terminal branches was correlated with an absence of overlying terminal SCs.

These results demonstrate that reactive SCs, in the absence of exogenous GGF2, can induce the retraction of nerve terminal branches from endplates. Furthermore, these data suggest that the integrity of an endplate is dependent on the stability of its terminal SCs and that the loss of nerve terminals in GGF2treated muscles is likely mediated by the changes this factor induces in terminal SCs.

\section{GGF2 fails to induce synaptic loss from adult neuromuscular junctions}

During the early postnatal period, SCs express the neuregulin receptors erbB2 and erbB3. After the second postnatal week, however, erbB2 expression in SCs is dramatically decreased (Cohen et al., 1992; Grinspan et al., 1996). Although adult SCs continue to express erbB3 (Grinspan et al., 1996), erbB3 lacks intrinsic kinase activity and in the absence of other members of the neuregulin receptor family is incapable of signal transduction (Carraway and Cantley, 1994; Sliwkowski et al., 1994). Because SCs apparently do not express erbB4 in vivo (Grinspan et al., 1996), adult SCs are likely to have substantially decreased responsiveness to neuregulin. Myofibers in adult muscle, however, remain competent to respond to neuregulin, because they continue to express the neuregulin receptors erbB2, erbB3, and erbB4 (Altiok et al., 1995; Moscoso et al., 1995; Zhu et al., 1995). Therefore, to examine whether the developmental decrease in SC responsiveness to neuregulin altered the ability of exogenous GGF2 to induce nerve terminal retraction, we administered exogenous GGF2 to muscles in P30 rats.

P30 rat soleus muscles exposed to GGF2 for $5 \mathrm{~d}(n=2)$ produced $90 \%$ of the twitch tension of contralateral, control

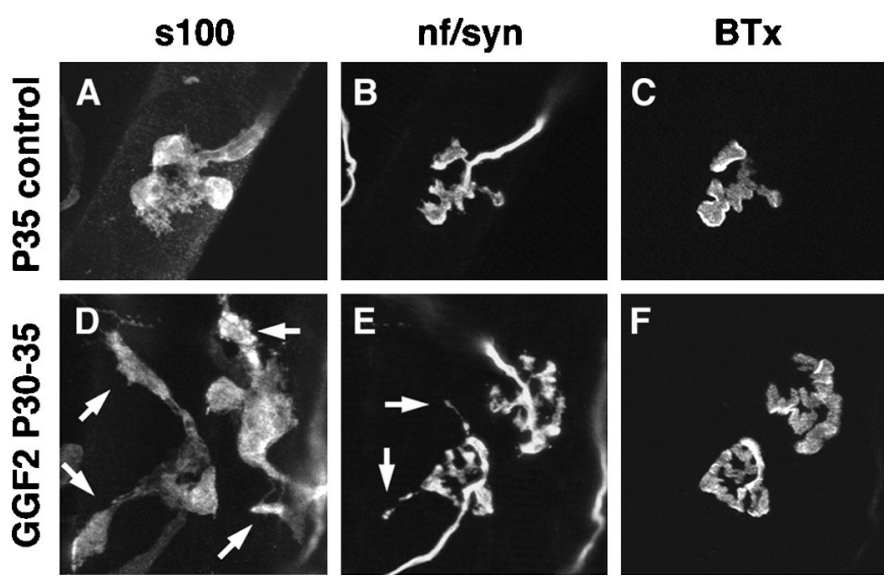

Figure 7. Nerve terminals are stably maintained in GGF2-treated adult muscles. Junctions are labeled as in Figure 2. $A-C$, A junction from a control P35 soleus muscle. Three terminal SCs $(A)$ are present covering the nerve terminal branches $(B)$ at this synapse. AChRs $(C)$ are completely covered by the overlying nerve terminal. $D, E$, Two junctions from a P35 soleus muscle treated with GGF2 for $5 \mathrm{~d}$ beginning on P30. The terminal SCs $(D)$ at both of these junctions had extended processes (arrows), although nerve terminal sprouts $(E)$ were seen only at the lower junction (arrows in $E$ ). Nerve terminal branches cover the underlying AChRs $(F)$ in their entirety. Scale bar, $30 \mu \mathrm{m}$.

muscles. Morphologically, the branching pattern of nerve terminals was not noticeably different between experimental and control muscles (compare Fig. 7, $B$ and $E$ ), although small ultraterminal sprouts $<20 \mu \mathrm{M}$ long were observed at $21 \%$ of the nerve terminals examined in GGF2-treated muscles (94 endplates examined in two muscles) (Fig. 7E). Interestingly, terminal SCs had extended processes at $82 \%$ of the endplates examined (Fig. $7 D$ ). The relative paucity of nerve terminal sprouts relative to SC processes suggests that SC processes in these muscles were poor inducers of axonal outgrowth. Although altered in their morphology, terminal SCs remained clustered around endplates and covered fully the underlying nerve terminal branches (Fig. 7D). No changes in the intensity or organization of AChR clusters were observed in these muscles (Fig. $7 F$ ). Similar changes were seen in the levator aurus longus, a superficial muscle in the head comprising only four muscle fiber layers (Angaut-Petit et al., 1987). In this case, there were no overlying barriers preventing the penetration of the trophic factor, and thus the absence of GGF2induced withdrawal in adults is unlikely to be attributable to the growth of the muscles overlying the soleus.

Although SCs retain a limited ability to respond to neuregulin in adult muscles, as evidenced by their extension of processes, these changes do not appear to be sufficient to adversely affect the stability of motor nerve terminals. These results demonstrate a critical period for GGF2-induced synaptic loss that is correlated 

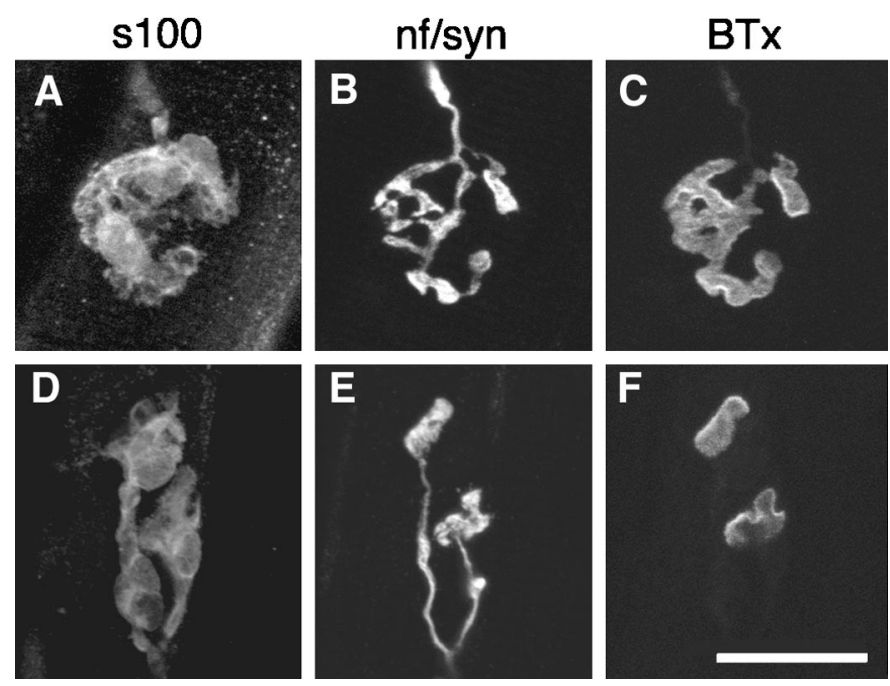

Figure 8. Neuromuscular junctions are reformed after GGF2 withdrawal. $A-C$, A junction in a normal 7-week-old soleus muscle. $D-F$, A junction in a soleus muscle treated with GGF2 from P4 through P9 and allowed to recover for 6 weeks. Junctions were triple-labeled as in Figure 2 . Note the simplicity of the recovered junction compared with a normal junction of the same age. Scale bar, $30 \mu \mathrm{m}$.

with the expression of high levels of functional neuregulin receptors in SCs. Interestingly, this critical period is also correlated with the expression of neuregulin in the juxtasynaptic regions of developing muscle fibers (Moscoso et al., 1995). Thus, the expression of this membrane-bound neuregulin by the muscle fiber may influence the responsiveness (e.g., migration) of terminal SCs to exogenous, soluble neuregulin.

\section{Neuromuscular junctions are reestablished after the cessation of GGF2 treatment}

To examine whether the loss of synaptic connectivity induced by exogenous GGF2 in neonatal soleus muscles was permanent or whether muscles could recover from such treatment, we administered GGF2 as above to hindlimb muscles of P4 rats for $5 \mathrm{~d}$ and then allowed the animals to recover from the treatment for 6 weeks $(n=2)$. The strength of nerve-evoked twitch contractions in recovered soleus muscles was 74 and $81 \%$ of the contralateral soleus muscles, demonstrating that functional neuromuscular connections had been reestablished. Additionally, grading the intensity of nerve stimulation and counting the number of increments in the muscle twitch tension (cf. Thompson and Jansen, 1977) showed that recovered muscles were innervated by $22-24$ motor neurons, a motor unit number similar to that of normally innervated, adult muscles (21-27). Thus, despite their disconnection from muscle fibers, motor neurons survived when treated with GGF2 for $5 \mathrm{~d}$.

Nerve terminals in recovered muscles (Fig. $8 E$ ) were very simple, with fewer branch points and with what appeared qualitatively to be a smaller area of innervation than nerve terminals in control muscles (Fig. 8B). Often, a single motor axon would form two small, separate terminals in close proximity on the same muscle fiber (Fig. 8E). Nerve terminals were not restricted to a well defined band in the center of these muscles as they were in control muscles. In one muscle, for example, neuromuscular junctions were seen adjacent to Golgi tendon organs, sensory structures found in myotendonous regions of muscles. AChRs were intensely labeled and well organized below nerve terminal branches in recovered muscles (Fig. 8F). Aneural AChR clusters were not observed, and terminal SCs were present at all nerve terminals (Fig. 8D). These results demonstrate that synaptic connections, dismantled by exogenous GGF2 application, are reestablished after cessation of GGF2 administration.

\section{DISCUSSION}

The terminal SCs that cap the neuromuscular junction have previously been demonstrated to play a role in the response of motor nerves to disruption of muscle innervation. These cells extend processes that appear to guide regenerating axons and to induce and guide neuronal sprouting. The results reported here suggest that the role of these cells extends beyond repair of muscle innervation. Our results suggest that SCs are able to induce rearrangements in the synaptic apposition of nerve terminals and their muscle fiber targets, i.e., to alter the efficacy of these synapses. Additionally, our results suggest that the stability of terminal SCs at developing nmjs, and thus the stability of the synapse as a whole, is sensitive to changes in the levels of synaptic neuregulins.

\section{Nerve terminal withdrawal and sprouting induced by neuregulin}

Exogenous neuregulin dismantles the nerve terminals in neonatal muscle, causing the nerve to retract from the synaptic specializations on the muscle fibers. Subsequently, axons grow robustly throughout the muscle, apparently following processes extended by migrating SCs. The continued presence of neuregulin seems to prevent the sprouted axons from forming synapses on the now denervated muscle fibers; however, synapses reform after withdrawal of neuregulin. Three questions arise concerning these findings: where does neuregulin act, how does neuregulin act, and what is the relevance of these neuregulin effects to the normal formation and maintenance of neuromuscular junctions?

\section{Where does neuregulin act?}

Both muscle fibers and terminal SCs are known targets of neuregulin, possessing receptors whose activation leads to the local expression of AChRs in muscle fibers, and to proliferation, migration, and survival in Schwann cells (Carraway and Burden, 1995; Lemke, 1996). Definitive information on the expression of neuregulin receptors by motor axons is presently lacking, but neuregulins are known to directly affect the survival and neurite extension of retinal neurons in culture (Bermingham-McDonogh et al., 1996). It is therefore possible that all three cell types present at the junction are neuregulin targets; however, we believe, on the basis of several observations, that the effects of exogenous neuregulin seen in this study are the result of its actions on terminal SCs. First, the retraction of nerve terminals is correlated with alterations in terminal SC morphology and in their coverage of junctions. Because these SC changes occur in neuregulin-treated denervated muscles as well as in cultured SCs, they are not likely attributable to neuregulin action on motor axons or muscle fibers. Second, the sensitivity of the synapse to neuregulin-induced disruption occurs during the period of early development when SCs express high levels of the erbB2 receptor and when neuregulin administration induces SC proliferation and migration. In contrast, in P30 muscles, an age at which SC expression of functional neuregulin receptors is reported to be greatly reduced but expression in muscle fibers is augmented (Cohen et al., 1992; Altiok et al., 1995; Moscoso et al., 1995; Z hu et al., 1995; Grinspan et al., 1996), synapses are far less responsive to neuregulin treatment. Third, transplanted Schwann cells that grow into contact with otherwise normal junctions produce a 
phenotype similar to that seen with neuregulin administration: the organization of Schwann cells over the junction is perturbed, and large portions of the nerve terminals are displaced from the postsynaptic apparatus. Fourth, we did not find any musclespecific changes in the P11-P16 muscles, assayed on the basis of postsynaptic AChR density and muscle fiber diameter, that were correlated with axon withdrawal. To be sure, these are gross measures of postsynaptic change, and we cannot exclude the possibility that neuregulin acts on the muscle fibers to change their production of retrograde signals important for maintenance of nerve terminals. Changes in such signals would not have been detected in our experiments. It should be noted, however, that even in the complete absence of a postsynaptic muscle fiber, portions of nerve terminal branches are maintained at the mammalian nmj (Rich and Lichtman, 1989b; Van Mier and Lichtman, 1994) and functional terminals remain at the frog nmj (Dunaevsky and Connor, 1995), suggesting that in addition to the muscle fiber, the basal lamina and other cell types at the nmj influence nerve terminal stability. On the basis of our data, we argue that terminal SCs play a role in regulating the stability of neuromuscular junctions.

\section{How might neuregulin-induced changes in terminal SCs cause the withdrawal of nerve terminals?}

There are a number of mechanisms by which neuregulins, acting through terminal SCs, could influence the stability of nerve terminals. Morphological studies have suggested that processes extended by SCs may physically intrude between pre- and postsynaptic cells during the removal of degenerating motor nerve terminals from muscle fibers (Bixby, 1981), during the loss of synaptic inputs onto axotomized neurons (Matthews and Nelson, 1975), and during the disruption of the neuromuscular junction in S-laminin knockout mice (Noakes et al., 1995). Neuregulin may cause SCs to intervene in a similar manner. Alternatively, or in conjunction, neuregulins could alter trophic interactions between SCs and nerve terminals that in turn alter the synapses. Neuregulins stimulate cultured SCs to secrete neurotrophic factors that promote neurite growth from cultured superior cervical ganglion explants (Mahanthappa et al., 1996), and in peripheral ganglia neuregulins stimulate non-neuronal cells (presumably SCs) to produce neurotrophins that affect the survival and differentiation of neurons (Verdi et al., 1996). Another possibility is that nerve terminals simply cannot be maintained in the absence of terminal SCs, and thus the neuregulin-induced migration of terminal SCs off endplates is sufficient to induce nerve terminal withdrawal.

\section{What is the physiological relevance of the terminal disruption observed in this study?}

Neuromuscular junctions are remodeled during both early development and aging. The mechanisms underlying this remodeling are incompletely understood. Participation of glial cells in synaptic remodeling has been suggested by Pomeroy and Purves (1988), who observed that changes in the position and numbers of SCs correlate with synaptic remodeling occurring in parasympathetic ganglia. We believe that the data presented here show that SCs have the potential to modify synaptic structure. Whether they participate in the remodeling of synaptic structure during early development and aging remains to be determined.

The results of the SC transplant experiments provide an explanation of a previously observed plasticity at the nmj. Bixby and Van Essen (1979) reported that foreign axons transplanted to the vicinity of normal neuromuscular junctions succeed in establishing synaptic contact with some host muscle fibers at their original synaptic sites. In many cases, these foreign axons even displace the original innervation. Because innervated and active muscle fibers are normally refractory to synaptogenesis at new sites by implanted axons (Jansen et al., 1973) and because the apposition of nerve terminals to the postsynaptic apparatus appears remarkably stable in young adult animals (Lichtman et al., 1987), the ability of the transplanted axons to establish any contact is surprising; however, SCs as well as axons emerge from such transplants, and we have shown here that these SCs cause host nerve terminals to vacate some synaptic sites. We suggest that these vacant synaptic sites enable the foreign axons to establish a foothold and compete with the original axons.

Although the neuregulin-induced changes in synaptic organization reported here are certainly more extreme than the changes that occur during normal development, a number of these changes do occur in a less robust form. For example, nerve terminals extend and retract small sprouts (Balice-Gordon et al., 1993), terminal branches are progressively withdrawn as they are eliminated from neuromuscular junctions (Balice-Gordon et al., 1993; Colman et al., 1997), the number of terminal SCs increases as SCs migrate to terminals from the endoneurial tube (Love and Thompson, 1996), and the relationships of SCs and axons must change as these additional cells are accommodated. Interestingly, the levels of neuregulin are also changing. Moscoso et al. (1995) reported that levels of neuregulin $\beta 1$ expressed by muscle fibers peak during early postnatal life and decrease thereafter to undetectable levels in adult muscles. Last, neuregulin-mediated signaling from axons to SCs is believed to trophically maintain terminal SCs in the neonate (Trachtenberg and Thompson, 1996). Thus, the neuregulin-induced changes in terminal SCs and motor nerve terminals that we report here are likely to be an exaggeration of naturally occurring events.

Although the levels of neuregulin used in our experiments (7.3 $\mu \mathrm{g} / \mathrm{d}$ ) are unlikely to occur in vivo, metabolism of the factor, its binding to proteoglycans (Sudhalter, et al., 1996) and other macromolecules, and its diffusion to the soleus muscle from the injection sites would decrease the amount of factor that ultimately affected nmjs. Tenfold lower doses of GGF2 $(0.73 \mu \mathrm{g} / \mathrm{d})$ also induced synaptic disruption, but in these muscles changes were limited to the lateral and medial edges of the soleus muscle that were closest to the site of injection and thus were not included in this study.

\section{Possible interactions between agrin and neuregulin signaling pathways}

Agrin, a factor initially characterized by the ability of the neural isoform to induce the clustering of AChRs on cultured myotubes (Godfrey et al., 1984; Nitkin et al., 1987), appears to modulate the responsiveness of muscle to neuregulin. Rimer et al. (1996) reported that transfection-induced expression of neural agrin at ectopic sites in muscle induces the clustering of erbB2, erbB3, and transmembrane isoforms of neuregulin. Furthermore, deficits in erbB receptor clustering are displayed in mice lacking agrin (Gautam et al., 1996) or MuSK, a signaling portion of the putative muscle receptor for agrin (DeChiara et al., 1996; Glass et al., 1996). Results reported here demonstrate that prolonged exposure of developing muscles to exogenous neuregulin produces a pattern of innervation that is strikingly similar to that reported in muscles from agrin-deficient mice (Gautam et al., 1996), including robust axonal sprouting, a paucity of nerve terminal special- 
izations, and a proliferation of aneural AChR clusters. Moreover, exogenous administration of neuregulin at the earliest neonatal ages in this study accelerates the denervation-induced dispersal of AChRs, suggesting that it alters the clustering activity of agrin present at synaptic sites. Taken together, these results suggest that nmj development is orchestrated in part by interactions between the agrin and neuregulin signaling pathways.

\section{REFERENCES}

Altiok N, Bessereau J-L, Changeux JP (1995) ErbB3 and ErbB2/neu mediate the effect of heregulin on acetylcholine receptor gene expression in muscle: differential expression at the endplate. EMBO J 14:4258-4266.

Angaut-Petit D, Molgo J, Connold AL, Faille L (1987) The levator auris longus muscle of the mouse: a convenient preparation for studies of short- and long-term presynaptic effects of drugs or toxins. Neurosci Lett 82:83-88.

Balice-Gordon RJ, Chua CK, Nelson CC, Lichtman JW (1993) Gradual loss of synaptic cartels precedes axon withdrawal at developing neuromuscular junctions. Neuron 11:801-815.

Balice-Gordon RJ, Lichtman JW (1993) In vivo observations of pre- and postsynaptic changes during the transition from multiple to single innervation at developing neuromuscular junctions. J Neurosci 13:834-855.

Balice-Gordon RJ, Lichtman JW (1994) Long-term synapse loss induced by focal blockade of postsynaptic receptors. Nature 372:519-524.

Bermingham-McDonogh O, McCabe KL, Reh TA (1996) Effects of GGF/neuregulins on neuronal survival and neurite outgrowth correlate with erbB2/neu expression in developing rat retina. Development 122:1427-1438.

Bixby JL (1981) Ultrastructural observations on synapse elimination in neonatal rabbit skeletal muscle. J Neurocytol 10:81-100.

Bixby JL, Van Essen DC (1979) Competition between foreign and original nerves in adult mammalian skeletal muscle. Nature 282:726-728.

Campagna JA, Rüegg MA, Bixby JL (1995) Agrin is a differentiationinducing "stop signal" for motoneurons in vitro. Neuron 15:1365-1374.

Carraway III KL, Burden SJ (1995) Neuregulins and their receptors. Curr Opin Neurobiol 5:606-612.

Carraway III KL, Cantley LC (1994) A neu acquaintance for erbB3 and erbB4: a role for receptor heterodimerization in growth signaling. Cell 78:5-8.

Chu GC, Moscoso LM, Sliwkowski MX, Merlie JP (1995) Regulation of the acetylcholine receptor epsilon subunit gene by recombinant ARIA: an in vitro model for transynaptic gene regulation. Neuron 14:329-339.

Cohen JA, Yachnis AT, Arai M, Davis JG, Scherer SS (1992) Expression of the neu proto-oncogene by Schwann cells during peripheral nerve development and Wallerian degeneration. J Neurosci Res 31:622-634.

Colman H, Nabekura J, Lichtman JW (1997) Alterations in synaptic strength preceding axon withdrawal. Science 275:356-361.

Corfas G, Fischbach GD (1993) The number of $\mathrm{Na}^{+}$channels in cultured chick muscle is increased by ARIA, an acetylcholine receptorinducing activity. J Neurosci 13:2118-2125.

DeChiara TM, Bowen DC, Valenzuela DM, Simmons MV, Poueymirou WT, Thomas S, Kinetz E, Compton DL, Rojas E, Park JS, Smith C, DiStefano PS, Glass DJ, Burden SJ, Yancopoulos GD (1996) The receptor tyrosine kinase MuSK is required for neuromuscular junction formation in vivo. Cell 85:501-512.

Del Castillo J, Katz B (1954) Quantal components of the end-plate potential. J Physiol (Lond) 124:560-573.

Descarries L, Marier C, Robitaille R (1996) NO synthase localization at the frog neuromuscular junction. Soc Neurosci Abstr 22:309.

Dunaevsky A, Connor EA (1995) Long-term maintenance of presynaptic function in the absence of target muscle fibers. J Neurosci 15:6137-6144.

Gassmann M, Casagranda F, Orioli D, Simon H, Lai C, Klein R, Lemke G (1995) Aberrant neural and cardiac development in mice lacking the ErbB4 neuregulin receptor. Nature 378:390-394.

Gautam M, Noakes PG, Moscoso L, Rupp F, Scheller RH, Merlie JP, Sanes JR (1996) Defective neuromuscular synaptogenesis in agrindeficient mutant mice. Cell 85:525-535.

Glass DJ, Bowen DC, Stitt TN, Radziejewski C, Bruno J, Ryan TE, Gies DR, Shah S, Mattsson K, Burden SJ, DiStefano PS, Valenzuela DM,
DeChiara TM, Yancopoulos GD (1996) Agrin acts via a MuSK receptor complex. Cell 85:513-523.

Glicksman MA, Sanes JR (1983) Differentiation of motor nerve terminals formed in the absence of muscle fibers. J Neurocytol 12:661-671.

Godfrey EW, Nitkin RM, Wallace BG, Rubin LL, McMahan UJ (1984) Components of Torpedo electric organ and muscle that cause aggregation of acetylcholine receptors on cultured muscle cells. J Cell Biol 99:615-627.

Goodearl ADJ, Yee AG, Sandrock AW, Corfas G, Fischbach GD (1995) ARIA is concentrated in the synaptic basal lamina of the developing chick neuromuscular junction. J Cell Biol 130:1423-1434.

Grinspan JB, Marchionni MA, Reeves M, Coulaloglou M, Scherer SS (1996) Axonal interactions regulate Schwann cell apopotosis in developing peripheral nerve: neuregulin receptors and the role of neuregulins. J Neurosci 16:6107-6118.

Harris DA, Falls DL, Dill-Devor RM, Fischbach GD (1988) Acetylcholine receptor-inducing factor from chicken brain increases the level of mRNA encoding the receptor alpha subunit. Proc Natl Acad Sci USA 85:1983-1987.

Jansen JKS, Lomo T, Nicolaysen K, Westgaard RH (1973) Hyperinnervation of skeletal muscle fibers: dependence on muscle activity. Science 181:559-561.

Jo SA, Zhu X, Marchionni MA, Burden SJ (1995) Neuregulins are concentrated at nerve-muscle synapses and activate ACh-receptor gene expression. Nature 373:158-161.

Ko PK, Anderson MJ, Cohen MW (1977) Denervated skeletal muscle fibers develop discrete patches of high acetylcholine receptor density. Science 196:540-542.

Kuffler DP (1986) Accurate reinnervation of motor end plates after disruption of sheath cells and muscle fibers. J Comp Neurol 250:228-235.

Lee KF, Simon H, Chen H, Bates B, Hung MC, Hauser C (1995) Requirement for neuregulin receptor erbB2 in neural and cardiac development. Nature 378:394-398.

Lemke G (1996) Neuregulins in development. Mol Cell Neurosci 7:247-262.

Lichtman JW, Magrassi L, Purves D (1987) Visualization of neuromuscular junctions over periods of several months in living mice. J Neurosci 7:1215-1222.

Liley AW (1956) The quantal components of the mammalian end-plate potential. J Physiol (Lond) 133:571-587.

Love FM, Thompson WJ (1996) Rat neuromuscular junctions gain terminal Schwann cells during postnatal development. Soc Neurosci Abstr 22:586.

Mahanthappa NK, Anton ES, Matthew WD (1996) Glial growth factor 2, a soluble neuregulin, directly increases Schwann cell motility and indirectly promotes neurite outgrowth. J Neurosci 16:4673-4683.

Marchionni MA, Goodearl ADJ, Chen MS, Bermingham-McDonogh O, Kirk C, Hendricks M, Danehy F, Misumi D, Sudhalter J, Kobayashi K, Wroblemski D, Lynch C, Baldassare M, Hiles I, Davis JB, Hsuan JJ, Totty NF, Otsu M, McBurney RN, Waterfield MD, Stroobant P, Gwynne D (1993) Glial growth factors are alternatively spliced erbB2 ligands expressed in the nervous system. Nature 362:312-318.

Marshall LM, Sanes JR, McMahan UJ (1977) Reinnervation of original synaptic sites on muscle fiber basement membrane after disruption of the muscle cells. Proc Natl Acad Sci USA 74:3073-3077.

Martinou JC, Falls DL, Fischbach GD, Merlie JP (1991) Acetylcholine receptor-inducing activity stimulates expression of the epsilon-subunit gene of the muscle acetylcholine receptor. Proc Natl Acad Sci USA 88:7669-7673.

Matthews MR, Nelson VH (1975) Detachment of structurally intact nerve endings from chromatolytic neurones of rat superior cervical ganglion during the depression of synaptic transmission induced by post-ganglionic axotomy. J Physiol (Lond) 245:91-135.

Meyer D, Birchmeier C (1995) Multiple essential functions of neuregulin in development. Nature 378:386-390.

Morrissey TK, Levi ADO, Nuijens A, Sliwkowski MX (1995) Axoninduced mitogenesis of human Schwann cells involves heregulin and p185erbB2. Proc Natl Acad Sci USA 92:1431-1435.

Moscoso LM, Chu GC, Gautam M, Noakes PG, Merlie JP, Sanes JR (1995) Synapse-associated expression of an acetylcholine receptorinducing protein, ARIA/heregulin, and its putative receptors, ErbB2 and ErbB3, in developing mammalian muscle. Dev Biol 172:158-169.

Nitkin RM, Smith MA, Magill C, Fallon JR, Yao Y-MM, Wallace BG, 
McMahan UJ (1987) Identification of agrin, a synaptic organizing protein from Torpedo electric organ. J Cell Biol 105:2471-2478.

Noakes PG, Gautam M, Mudd J, Sanes JR, Merlie JP (1995) Aberrant differentiation of neuromuscular junctions in mice lacking s-laminin/ laminin $\beta 2$. Nature 374:258-262.

Patton BL, Sanes JR (1996) Evidence that S-laminin/laminin- $\beta 2$ has a direct role in synaptic regulation of Schwann cells in vivo at the neuromuscular junction. Soc Neurosci Abstr 22:586.

Pomeroy SL, Purves D (1988) Neuron/glia relationships observed over intervals of several months in living mice. J Cell Biol 107:1167-1175.

Reynolds ML, Woolf CJ (1992) Terminal Schwann cells elaborate extensive processes following denervation of the motor endplate. J Neurocytol 21:50-66.

Rich MM, Lichtman JW (1989a) In vivo visualization of pre- and postsynaptic changes during synapse elimination in reinnervated mouse muscle. J Neurosci 9:1781-1805.

Rich M, Lichtman JW (1989b) Motor nerve terminal loss from degenerating muscle fibers. Neuron 3:677-688.

Riley DA (1981) Ultrastructural evidence for axon retraction during the spontaneous elimination of polyneuronal innervation of the rat soleus muscle. J Neurocytol 10:425-440.

Rimer M, Cohen I, Lomo T, Burden SJ, McMahan UJ (1996) Neural agrin induces aggregation of muscle-derived ARIA, and its receptors erbB 2 and 3, in adult rat soleus muscle. Soc Neurosci Abstr 22:665.

Sanes JR, Marshall LM, McMahan UJ (1978) Reinnervation of muscle fiber basal lamina after removal of myofibers: differentiation of regenerating axons at original synaptic sites. J Cell Biol 78:176-178.

Sandrock AW, Dryer SE, Theill LE, Fischbach GD (1996) Altered ARIA/neuregulin expression affects both pre- and post-synaptic components of neuromuscular transmission. Soc Neurosci Abstr 22:665.
Slater CR (1982) Neural influence on the postnatal changes in acetylcholine receptor distribution at nerve-muscle junctions in the mouse. Dev Biol 94:23-30.

Sliwkowski MX, Schaefer G, Akita RW, Lofgren JA, Fitzpatrick VD, Nuijens A, Fendly BM, Cerione RA, Vandlen RL, Carraway III KL (1994) Coexpression of erbB2 and erbB3 proteins reconstitutes a high affinity receptor for heregulin. J Biol Chem 269:14661-14665.

Son Y-J, Thompson WJ (1995) Nerve sprouting in muscle is induced and guided by processes extended by Schwann cells. Neuron 14:133-141.

Sudhalter J, Whitehouse L, Rusche JR, Marchionni MA, Mahanthappa NK (1996) Schwann cell heparan sulfate proteoglycans play a critical role in glial growth factor/neuregulin signaling. Glia 17:28-38.

Thompson W, Jansen JKS (1977) The extent of sprouting of remaining motor units in partly denervated immature and adult rat soleus muscle. Neuroscience 2:523-535.

Trachtenberg JT, Thompson WJ (1996) Schwann cell apoptosis at developing neuromuscular junctions is regulated by glial growth factor. Nature 379:174-177.

Van Mier P, Lichtman JW (1994) Regenerating muscle fibers induce directional sprouting from nearby nerve terminals: studies in living mice. J Neurosci 14:5672-5686.

Verdi JM, Groves AK, Fariñas I, Jones K, Marchionni MA, Reichardt LF, Anderson DJ (1996) A reciprocal cell-cell interaction mediated by NT-3 and neuregulins controls the early survival and development of sympathetic neuroblasts. Neuron 16:515-527.

Zhu X, Lai C, Thomas S, Burden SJ (1995) Neuregulin receptors, erbB3 and erbB4, are localized at neuromuscular synapses. EMBO J 14: 5842-5848. 